\title{
Research on Government Supervision against the Background of Shared Economy
}

\author{
Yuetong Li \\ Wuhan university of technology \\ Wuhan, China
}

\begin{abstract}
With the rapid development of the sharing economy, people's way of life and the development of enterprises are affected. At the same time, some local governments have had a profound discussion on the governance mode and structure of the sharing economy. Sharing economy represents a new economic model, which has changed the traditional business model, reduced marginal cost, activated stock resources, and significantly improved the efficiency of economic operation. Therefore, on the basis of following the law of economic development, the government needs to establish and improve the government-led mode and carry out the governance mechanism of the government in a way of multi-subject cooperation. While perfecting the legislation, we should pay attention to the innovation of regulation, create the mode of benign competition and shape a fair market environment of sharing economy.
\end{abstract}

Keywords-Sharing economy; Existing problems; Government regulation

\section{THEORETICAL ELABORATION OF SHARING ECONOMY}

The emergence of sharing is the inevitable social and economic behavior of human beings under the restriction of strengthening social connections and effective resources. As for the Sharing Economy, the general theory holds that it is an economic and social system that enables the Sharing of goods, services, data and intelligence. That is to say, through certain media and operational mechanisms, a socio-economic ecosystem based on the Sharing of people's means of production and living is formed .Generally speaking, sharing economy is an economic form in which an organization or individual with idle resources transfers the right to use the resources to others for compensation (or free), and the transferor obtains a certain return (economic or non-economic return), and the sharer creates value by sharing the idle resources of others. In the current sharing economy, there are many forms, but in general, they all have a common feature, that is, with the development of information technology, mobile network plays a key role in the sharing economy. We cannot deny that the emergence of "sharing" is mainly due to the development of Internet, Internet of things and other information technologies. The development of Internet thinking in social culture has brought many influences on consumers' consumption and life, which makes the emergence and operation of new business models possible. At the same time, the development of the Internet and the gradual perfection of its supporting facilities have laid a profound foundation for the development of the sharing economy. Sharing economy mainly makes it possible for individuals, enterprises and other sufficient information, surplus resources and idle goods and services to be reused. Compared with the traditional economy, the creative development of the sharing economy lies in: First, it has changed the traditional relationship between production and elimination. More attention should be paid to human nature and sense of participation. Producers and consumers have equal choices. The hostile relationship between the traditional seller and the user turns into the cooperative relationship Second, pay more attention to equality and be more trustworthy. Based on the third-party network platform, information is more transparent and symmetrical, and transactions are "self-supervised" by the network, so that trust can be realized. Third, it changes the unlimited pursuit of ownership, saves resources and greatly improves the efficiency of resource utilization. Fourth, the diversity of Shared content. What sharing pursues is not necessarily commercial value or monetary value. The realization of its value can be based on the diversified appeal of human nature. It can be non-monetary or non-material value.

The driving force of sharing economy mainly comes from the change of user demand and the improvement of supplier technology. On the one hand, with the gradual rise of ecological concepts and the development of urbanization, some consumers are more inclined to rent rather than buy, and the development of urbanization makes people no longer limited to a certain area. The rapid mobility of population also brings more opportunities for the rise of Shared goods and services. On the other hand, people's ability to apply the network for data application and analysis has been constantly improved. The improvement of GPS positioning system brings new experience to users and service providers, which makes the information exchange between service providers and users more convenient and enables people to get services in a timely manner.

In the sharing economy, it is possible for everyone to participate. On the contrary, it is difficult to achieve the sharing economy with no one or few people. At the same time, it will attract more and more people to participate because it can reach a certain scale from the very beginning. The participation of everyone mentioned here is mainly from two aspects: on the one hand, everyone participates in supply; on the other hand, everyone participates in consumption. In the sharing economy, individuals are the main entities. The suppliers of goods and services are no longer strictly organized manufacturers, and the trivial individuals gather together through the sharing platform to produce social benefits. 


\section{Problems EXISTING IN CHINA'S SHARING ECONOMY}

\section{A. The disturbance caused by new social resources}

In terms of industrial forms, the emergence of new social resources is often accompanied by the elimination of old technologies and production systems. This characteristic in the Shared economic performance in the gradual development, most notably in new social resources and the old forces of competition, the competition in nature it is a kind of new products, new technology and new combinations of competition, sharing brings new market economy under the new social resources, also giving consumers more choice, there IS NO DOUBT THAT IS A REFLECTION OF SOCIAL DEVELOPMENT. AT THE same time, the sharing economy is "fatally destructive" because it further compresses profit margins in many industries, exposes traditional enterprises to transformation pressures and even threatens their survival. For example, in the taxi industry, taxi drivers need to comply with various regulations, accept the supervision of the company, and pay the corresponding fees, but didi and other operating drivers do not have any constraints.

The traditional supervision mode of the government is mainly based on the traditional social resources. However, with the emergence of new social resources in the sharing economy, the traditional supervision mode becomes vacant. In real life, it is difficult and ineffective to supervise. For example, the emergence of homestay, it is not a traditional hotel operator, but just an ordinary owner who has spare rooms for rent. On the one hand, the increasing number of guest sources of home stay homes affects the development of the hotel industry; on the other hand, due to the dissatisfaction of neighbors around home stay homes, residential areas have become the traditional hotel regional model. However, it is difficult to determine the quality of mediation in this process.

\section{B. Crisis of social credit system}

Sharing economy has the characteristics of non-professionalism, based on which the protection of consumers has become a difficult problem. For instance, the owners of homestay do not need to meet the relevant requirements of hotel management, and there are obviously huge loopholes in market regulation, safety supervision and other aspects. There are some illegal operations in the information on the sharing platform, which is easy for consumers to misunderstand. Since there is no legal business registration and business norms in the subsequent rights protection, it is also very difficult for consumers to protect their rights.

The development of sharing economy expands the communication between strangers, but the asymmetry of information exchange makes the sharing more uncertain, so the sharing platform should play a key role in it. However, most sharing platforms are difficult to conduct comprehensive and rigorous reviews for a variety of reasons. This makes it difficult to protect consumers' personal rights and property rights, such as the violation of female passengers by online ride-hailing, because of unprofessional traffic accidents and so on. In addition to these obvious external risks, there are also many hidden dangers in the sharing platform. For example, the imperfect protection mechanism of personal privacy makes many consumers' personal information be disclosed and used by criminals. What's more dangerous is that once the information is obtained by criminal groups to carry out fraudulent activities, the harm to individuals and society will be more serious.

In the face of these characteristics, traditional governance patterns and organizational forms show their advantages, and trust has become particularly important." The sharing activity brought about by the premise of trust is the igniter that activates the real economy, and the sharing activity is completely dependent on the establishment or improvement of the cultivation mechanism of trust". Trust is the basis of the operation of the sharing economy, but trust has always been the biggest obstacle to the development of the sharing economy. At present, sharing platforms are also aware of the existence of trust problems, they generally use star rating, user complaints, qualification audit and other mechanisms to improve trust and protect consumers' right to know, however brushing, fake sales, malicious harassment and poor rating behavior is becoming more and more widespread. The imperfection of social credit system restricts the development of sharing economy, which makes some sharing platforms have to reduce the scale to prevent greater losses.

\section{PRomote TARGETED DEVELOPMENT OF THE GOVERNMENT'S GOVERNANCE SYSTEM AND CAPACITY BUILDING}

Faced with the continuous emergence of new things in the sharing economy, the government also needs to make changes to the traditional governance decisions. This requires the government to clearly recognize the law of the development of the sharing economy, and continuously improve the problems existing in the governance of the sharing economy, so as to provide a good social environment for the rapid development of the sharing economy, make government governance more active and effective, and ensure the steady development of the sharing economy and society.

1) Actively study the laws governing the development of the sharing economy

Under the social background of the gradual development of the sharing economy, the governance of the government needs to actively conform to the laws and models of science, technology and economic development. Only when we have a clear understanding of the law of social development, we will be familiar with the contradiction between the original government management mode and vested interests and the current social development, and make timely judgments on the weak economic environment and complex decision-making factors.

At present, as a new concept, sharing economy has gradually emerged in many specific problems and characteristics in different industries, such as sharing economy in the financial field and public travel field. Its business model and scope of influence are deeply branded by the industry. This requires the government to deeply understand and study the development trend of sharing economy in each industry and the changes in each industry, and make accurate classification management according to the characteristics of each industry, 
so as to achieve active adjustment, benefit avoidance and timely guidance at the management level. In addition, in the development of the sharing economy, it will show different characteristics at different stages, which requires the government to make normative and guiding Suggestions on the issues of principle and basic linearity, and establish the social supervision and management mechanism adapted to the new economic environment as soon as possible.

2) Gradually improve government governance systems and mechanisms suitable for the sharing economy

a) Improve the supervision and operation mechanism

The government should give full play to its core and dominant position in governance. First, the government should promote the gradual transparency of supply and demand information, so as to improve the quality of effective supply and demand, gradually eliminate the ideological transformation and institutional reform obstacles caused by the sharing economy, and put forward more detailed plans for the development planning of the sharing economy and the management of the Internet. In order to achieve the purpose of everyone's participation, the government needs to strengthen the effective supervision of market activities in the sharing economy while providing public services for the construction of Internet infrastructure, so as to realize the combination of supervision and encouragement of development. To improve the professional ability and level of government civil servants, they can actively face the social environment under the sharing economy, improve the combination of incentive measures and error correction mechanism, and realize the operation mechanism of decision-making, execution, supervision, restriction and coordination. Second is government agencies to coordinated regulatory model, in the areas of Shared economy respectively establish a comprehensive regulatory, Internet regulators, coordinated regulatory network market, perfect the mechanism of and enterprise collaboration between government departments, management mode and management system, perfect the market main body at the same time encourage the supervision of the masses, promoting social transformation. Three is to clarify the division of responsibilities between the central and local, standard operation regulation scope of responsibility, strengthen the central government to the unified national market share related to areas of economic and management rules, such as in the management of business services, security review, information infrastructure construction, at the same time strengthening the local government for supporting facilities, public services, market regulation, play an active leading role; Governments at all levels should have a clear grasp of resource channels under the sharing of big economic data, and formulate and implement policies in a unified manner. The superior government makes the summary and suggestion of the management in time to the new social phenomenon, the inferior government carries out the policy which the superior government makes positively to the effective implementation. b) Properly handle the relationship between innovation and regulation

As for a series of problems caused by the arrival of the sharing economy mentioned above, such as unemployment, difficulty in safeguarding consumers' rights, and labor security, these are inevitable short-term problems in the transformation of the old and new economic models. This requires the government to do a good job in basic supporting work, such as social security, law, tax, public security and other policies to mitigate the impact of transformation, rather than prohibit innovation. Generally speaking, the emergence of innovative economic model is always ahead of the process of law and system. If the traditional regulatory model is blindly used to govern and regulate the innovative economic model, the innovative economic model will be greatly constrained and hinder its development. Government departments should take into account the new features of the sharing economic model in their supervision, specifically analyze the rationality of the management system under the traditional economic model, and gradually innovate the supervision model to adapt to the economic development environment. The government should give full play to its leverage role in supervision. It should not only "let it go" to promote the development of the sharing economy model, but also "manage it" to improve the possible harm to social interests and public interests under the positive sharing economy model, and take timely actions to effectively control and punish them..

c) Construction of collaborative and open government governance system

The main feature of the sharing economy is the participatory model, which allows thousands of ordinary people to share resources and capabilities, thus building a self-management system. Didi, for example, realizes the management of drivers and vehicles through various ways and regulations, and the supervision of traffic management department is very insignificant. Under the mode of shared economy, the effectiveness of public affairs governance depends more and more on the mutual influence and benign interaction between government and citizens, society and enterprises. At the same time, the modernization of national governance also emphasizes the diversification of public affairs governance subjects and the networking of governance structure, and the boundary of government, market and society is gradually blurred. In the new era, the government needs continuous open innovation to mobilize all stakeholders to find high-quality and efficient solutions.

\section{CONCLUSIONS}

Sharing economy is a complex field. It is unrealistic and unreasonable to pursue stability only by containment. In order to find a more suitable mode to supervise the social formation of sharing economy, we should recognize the direction of development and the purpose of existence of sharing economy.

Sharing economy plays an important role in reducing information asymmetry and transaction costs, promoting the utilization of idle resources and promoting the speed of economic operation. As a new thing, the sharing economy also faces many problems, such as transaction security, credit system construction, consumer rights and interests maintenance 
and other issues need to be further improved and solved. However, I always believe that with the development of the

The reasonable mode of government regulation is the best way to realize social governance and the least cost to change society. At present, the development of sharing economy is faced with the problems of weak supervision and inadequate supervision, so we should strengthen the supervision on the one hand, and make up the regulatory loopholes on the other. The purpose of legal regulation of shared economy is to achieve the balance between the goals of encouraging innovation, protecting consumers and pursuing market efficiency, the core of which is the game between government power and market power. Under the background of encouraging innovation, streamlining administration and delegating power, China should follow the differences between the sharing economy and the traditional economic model, and treat the differences differently on the key issues of regulation. Looking at the current regulatory measures, it is suggested to adopt incentive methods, gradually relax the requirements of market access, and combine platform operation with market regulation. To sum up, the regulation of the sharing economy is an issue involving many subjects, involving a wide range of fields and having a wide range of influences. In a word, the regulation of the sharing economy is a problem involving many subjects, involving a wide range of fields, and having a wide sharing economy and the improvement of the rules and regulations, people's living standards will be improved.

range of influence. Complete strict enforcement may not only kill the sharing economy, but simply relaxing the supervision will also bring many social problems. It is necessary to establish a new mode of government supervision in order to realize proper regulation of shared economy.

\section{REFERENCES}

[1] Rachel Botsman. The Sharing Economy Lacks Shared Definition [EB/OL]. [2016-03-17]. http: // www.Fastcoexist.com/ 3022028/ the sharing economy lacks shared definition.

[2] Yao Yu-dong, Yang Tao. Share Finance-A breakthrough in financial theory in the era of great change [N]. Shanghai Securities News, 2015-09-08. (009). Jeremy Rifkin, 2015, towards the Internet of things and the shared economy, Enterprise Research, No. 2, pp. 14-21.

[3] Sun Zhichao, shared economy: the Law of Trust value, http: / sunzhichao. Baijia. Baidu. Com / article / 32171.

[4] Xue Lan, Li Yuhuan, 2014. The Transformation of Government functions towards the Modernization of State Governance: systematic thinking and Reform orientation. Political Science Studies, No. 5, pp. 61-70.

[5] Sandeep Vaheesan, "What Iron Pipefittings Can Teach Us About Public and Private Power in the Market," Indiana Law Journal Supplement,vol.91,2015,pp.15-23. 